\title{
Gold Price and Exchange Rate Volatility: Effects of Economic Sanctions
}

\author{
Bita Mashayekhi ${ }^{1}$, Mehrdad Sadr Ara $^{2}$, Ashraf Jafari ${ }^{3}$ \\ ${ }^{1}$ Associate Professor, Faculty of Management, University of Tehran, Iran \\ Email:mashaykhi@ut.ac.ir \\ ${ }^{2}$ Ph.D Student, Faculty of Management, University of Tehran, Iran \\ Email: MehrdadSadrAra@ut.ac.ir \\ ${ }^{3}$ Ph.D Student, University of Ataturk, Turkey \\ Email: Jafari Ashraf@yahoo.com
}

\begin{abstract}
The gold market has recently attracted much attention and gold prices have fluctuated over the past few years. Therefore, the aim of this study is investigate and analyze the trend of gold prices over the past five years in Iran. The importance of this topic is coming from uncertainty and volatility of the gold market, gold excitement and lack of a correct analysis of the market trends with reference to the probable factors which affect the gold price.

The study's period refers to the ended five-year in December 2012. This research from methodological point of view is a descriptive-perspective analysis that examines the influence of variables such as the gold price on the market, the official exchange rate and non-official rate on the Iran's market, the price of Brent crude oil, the global rate per ounce gold and foreign economic sanction. Vector auto regression model is used to analyze the results of the study. The results indicate that gold price is affected from exchange rates' fluctuations and gold global rate, it is also noteworthy to mention that the most important factors affecting the recent volatility in the Iran's gold market and the exchange rate is the economic sanctions which have been imposed against Iran.
\end{abstract}

Keyword: Gold Price; Exchange Rate; Economic Sanction

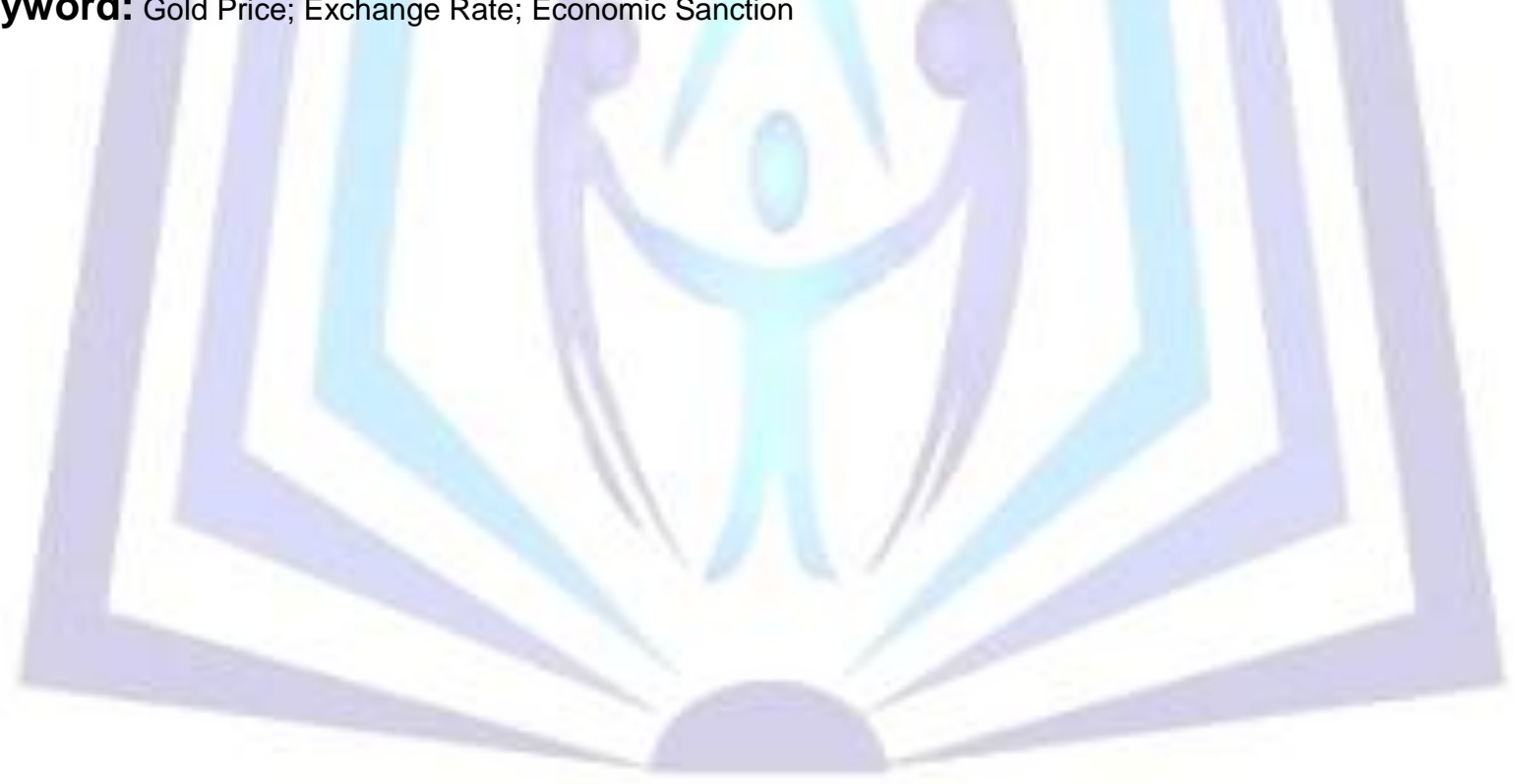

\section{Council for Innovative Research}

Peer Review Research Publishing System

Journal: International Journal of Management \& Information Technology

Vol.4, No.1
editor@cirworld.com
www.cirworld.com, member.cirworld.com 


\section{INTRODUCTION}

Gold is a precious metal which is also classed as a commodity and a monetary asset. It has acted as a multifaceted metal down through the centuries, possessing similar characteristics to money in that it acts as a store of wealth, medium of exchange and a unit of value [10,24]. Gold has also played an important role as a precious metal with significant portfolio diversification properties [5]. Gold is used in industrial components, jewellery, as an investment asset and reserve asset. Gold is a unique asset in that much of the gold ever mined still exists today. Approximately 2500 tonnes of gold is mined per annum. Above ground stocks account for 135,000 tonnes. Governments and investors account for approximately 60,000 tonnes, jewellery accounts for 63,000 tonnes and 15,000 tonnes is held in other forms such as electronics, etc. Gold is a highly liquid metal; it can be readily bought or sold every moment of day, in large denominations and at narrow spreads. This is highlighted by [7] who note that total annual production of gold is cleared by the London Bullion Market Association every 2.5 days [26].

While gold is an industrial metal, its uses are fewer compared to other metals, with only approximately $10 \%$ of gold demand derived from industry. Of perhaps more interest is gold's use as an investible metal. Central banks hold a large proportion of the above-ground stocks of gold [14]. Central banks and international financial institutions maintain 32,000 tonnes of gold in their reserve. Gold is held in central banks reserves for a number of reasons: diversification, economic security gold maintains its purchasing power, physical security gold is a liquid asset, confidence cushion in a crisis, maintains value, income gold leasing, insurance against market crises. Much research also points to the benefits of inclusion of gold holdings as leading to a more balanced portfolio [1, 5, 6, 7, 8, 13, 23].

In this research, at first we are going to mention necessity of performing of this survey here, then we will issue the theoretical literature of speech and background research to develop, after that it is suggested investigation methods and assumptions, and eventually work has been developed to be completed with estimating and analyzing the model.

At last, it should be noted that the aim of this study is to determine the behavior of the gold price in the emerging market of Iran in other words, determining the volatility's impact of global gold price, exchange rate fluctuations, oil price and economic sanctions' impact on gold price in Iran.

\section{REVIEW OF LITERATURE}

Recently, there has been a surge in interest in the movements of commodity prices and their relationships with major macro-economic variables. Commodity prices tend to rise and fall together over time [17]. The interest toward the Commodity prices' movement and its relationship to major macro-economic variables has been changed these days [25]. Commodity prices may have common movements because of changes in macroeconomic variables that affect demands and/or supplies for broad sets of commodities [17]. Due to same changes in macroeconomic variables which have effect on demands and supplies for a vast number of commodities, the commodity prices varied.

Commodity markets have undergone major changes during the last fifteen years. The popularity of commodity-related financial instruments, such as commodity indices, led many observers to consider that commodity markets were more deeply connected to financial markets [15]. In this regard, one point is tempted to ask whether the commodity phenomena that prevail globally would exist at the local level. It is also not clear whether the directional relationships among the prices are short lived or they persist in the long run. We are particularly interested in whether the oil price leads the commodity price procession as was recently believed, and whether this lead persists in the future in a developing country. The intellectual curiosity and policy pragmatism have focused on those commodities which include oil and precious metals particularly gold; because it is the most widely traded in commodity trading centers, priced in dollar and considered a hedge during flight to safety as a result of depreciation in the dollar exchange rate. The price of gold is the interest of this research but for the case of a developing country. This is why we selected these variables for this study [25].

Studies conducted on developed countries show short-lived relationships between oil, gold and silver, with gold having the edge over oil [20]. These short-run relationships have roots in the major commodities' sensitivities to changes in the business cycles and the US dollar exchange rate. But would the relationships strengthen if the interest rate is included in the system to link commodities to the exchange rate and monetary policy actions? While Baffes (2007) believes the interest rate should be included, the jury is still out on the significance of the link even in developed countries [2].

In recent research, it has been shown that there are various relationships between macroeconomic variables such as currency rate, inflation rate, oil prices and gold prices. Some of it research have been following.

Soytas et al. (2009), evaluated oil world price, precious metals price and macroeconomic variables in Turkey as a developing country. As trade and investment barriers are decreasing, the global investors closely watch the economic and financial developments in the emerging markets. Newly developed capital markets may be more prone to global shocks and have different macroeconomic dynamics than developed markets. Another important sensitivity that emerges in the case of developing markets is their strong obsession with gold. There is strong possession of gold in countries like Turkey, India, Indonesia and Saudi Arabia, among other developing countries. It will be interesting to find out if this possession of gold, and to lower extent silver, changes the relationships between oil and a developing country's domestically traded precious metals and also with its own macroeconomic variables, particularly the domestic interest rate and the domestic currency/Dollar exchange rate. For Turkey, the Lira/Dollar exchange rate and the interest rate are the domestic macroeconomic variables that will be included in this study. Such as that and with a little difference for Iran, the Riyal/Dollar (free market rate and official rate) and inflation rate are the domestic macroeconomic variables that will be included in this study. The results of Soytas's research are useful for domestic and international portfolio managers who diversify their portfolios by including bonds, commodities and other asset classes of developing countries like Turkey. In fact, according to Capital Markets Board of Turkey (2009) more than 70 percent of the stocks traded on ISE in 2007 were owned by foreign investors. The results are also helpful for the monetary authority who may be interested in knowing the linkages between their domestic interest rates and the main commodity prices to formulate economic policies [25]. 
In gold market there are two variables which have straight effects, these are two macroeconomic variable as oil price and inflation rate [26]. There is a positive correlation between gold and crude oil prices.

Shafiee \& Topal (2010), in their research about gold world markets and forecast of gold price, reviewed historical trend of gold price and affected by macro variables such as oil and world inflation during the 40 years ended 2008 . The results of model proposes that historical data of mineral commodities have three terms to demonstrate fluctuation of prices: a longterm trend reversion component, a diffusion component and a jump or dip component. The study validates the model and estimates the gold price for the next 10 years, based on monthly historical data of nominal gold price [22].

In the gold markets, in the short-term there are two main reasons why gold prices dramatically increase. Firstly, in a period where global financial markets crash and the global economy is in recession, investors are less trusting of financial markets as reliable investments. Consequently, they switch to speculation or to any market that does not have heavy liability or unpredictability, such as the gold market. In other words, the gold market operates as a type of insurance against extreme movements in the value of traditional assets during unstable financial markets. Secondly, the devaluation of the US dollar versus other currencies, and international inflation with high oil prices are reasons why big companies to hedge gold against fluctuations in the US dollar and inflation [22].

Pukthuanthong \& Roll (2011), experimentally showed that there is a negative relationship between gold price and Dollar rate. This means that when the Dollar price of gold increases, the Dollar depreciates against other currencies such as Euro, Pound and Yen. This is intuitively puzzling because it seems to suggest that gold prices are associated with appreciation in other currencies. Why should the Dollar be different? They show that there is actually no puzzle. The price of gold can be associated with currency depreciation in every country. The Dollar price of gold can be related to Dollar depreciation and also the Euro (Pound, Yen) price of gold can be related to Euro (Pound, Yen) depreciation [18].

Many economists and market analysts believe that gold spot prices are influenced by expected inflation. Analysts in the financial press routinely attribute substantial changes in the price of gold to changes in expected inflation. When unexpected changes in the Consumer Price Index (CPI) occur on the same day as large changes in the price of gold, analysts attribute the change in gold price to the changes in the inflation indicators. Even the Federal Reserve has indicated that gold prices and returns can be used as a measure of future inflation. Alan Greenspan, the recent past chairman of the Federal Reserve, has commented that the price of gold is "a very good indicator" of inflation and is useful in the battle against inflation [4].

\section{RESEARCH METHOD}

To do this study, we have used the daily gold prices, exchange rate (free market rate and official rate), inflation rate and global crude oil during a 5 year period from December 2007 to December 2012. Because of no significant difference between the price of a gram of gold with different carat and Bahare Azadi coin (old \& new version) we used daily price of old version Bahare Azadi coin during this period and with the symbol (GC) is shown. For other parameters the following symbols have been used.

For the global price of gold, gold price per ounce is used and with the symbol (GO) is shown. For the exchange rate we used two variables, free market rate in Tehran Market with the symbol (DR) and the official rate with the symbol (FR). For the next variable the Brent crude oil prices with symbol $(\mathrm{OW})$ and for the inflation rate with symbol (II), the total index of consumers on a daily basis during the five years leading up to December 2012 are used. Table 1 summarizes the descriptive- statistics of the variables.

Table 1: Descriptive statistics of variables

\begin{tabular}{|lcccccc|}
\hline & Gold Coin & Global Oil & Global Gold & Exchange Free Rate & Official Rate & Inflation Rate \\
Mean & 4176266 & 86.16494294 & 1253.56459 & 12515.62054 & 10426.13481 & 234.9319 \\
Std. Dev & 2433638.1 & 20.67822173 & 330.530309 & 4914.672501 & 931.489862 & 55.97554 \\
Skewness & 1.5522002 & -0.09431828 & 0.183212 & 2.443483403 & 0.840129459 & 0.840675 \\
Kurtosis & 2.2093557 & 0.420619879 & -1.4132904 & 6.135572394 & -0.14115859 & -0.165576 \\
Coeff. of Variation & 0.5827306 & 0.23998416 & 0.26367234 & 0.392683086 & 0.08934182 & 0.2382627 \\
Observation & 1402 & 1402 & 1402 & 1402 & 1402 & 1402 \\
\hline
\end{tabular}

As shown in Table 1, the price of gold based on coefficient of variation (CV) has the greatest volatility. It can be related to the shocks of the market, especially in the final year of study. The second volatile variable is the dollar's free rate which is not unexpected. In other words it can be said that the free market rate of the dollar is more stable than gold coin. Table 2 shows the correlation coefficients between variables.

Table 2: Correlation Coefficients Between Model's Variables

\begin{tabular}{|llllllll}
\hline & Gold Coin & Global Oil & Global Gold & Exchange Free Rate & Official Rate & Inflation Rate \\
Gold Coin & 1 & & & & & & \\
Global Oil & 0.254429757 & 1 & & & & & \\
Global Gold & 0.850727166 & 0.279679521 & 1 & & & \\
Exchange Free Rate & 0.947656601 & 0.151071292 & 0.67857927 & 1 & & \\
Official Rate & 0.881805974 & 0.06688868 & 0.82040786 & 0.846304127 & 1 & \\
Inflation Rate & 0.944948817 & 0.160932863 & 0.89352093 & 0.880344951 & 0.957853313 & 1 \\
\hline
\end{tabular}

As shown in Table 2, the highest correlation coefficient is between the official exchange rate and the inflation rate which is neglected because of its syntax. As also, gold coins and dollar exchange rate in free market have high relationship, because the both are endogenous variables and affected on exogenous variables such as world price of oil and world price of gold. in addition, despite the influence of exogenous variables, cause the shocks of the domestic economy (resulting from economic sanctions). 
Another point is about the political situation in Iran that led to the international statements of economic sanctions against Iran and is contribute to the designing model and its implications. Therefore, to specify the optimal model, the imposed variables on Iran's economy in the form of dummy variables included in the model. According to the survey done in 2008 so far, five formal statements against Iran by the UN Security Council released as follow:

Security Council Statement 1803 (which is shown by UN1) ${ }^{1}$,Security Council Statement 1835 (UN2) ${ }^{2}$, Security Council Statement 1929 (UN3) ${ }^{3}$, Security Council Statement 1984 (UN4) ${ }^{4}$ and Security Council Statement 2049 (UN5) ${ }^{5}$ [21].

\subsection{The Research Hypotheses}

This study examines the assumptions about Gold price and the currency market which is always controversial, especially in the current market conditions. Many studies about gold prices and exchange rates are shown positive relationship between them $[3,18]$. In this study, the gold price and exchange rate (USD) to Riyal is discussed. so, based on the results of different researches and expectation, the price of gold in domestic market is affected by fluctuations of exchange rate. Thus, the following hypotheses are stated.

$\boldsymbol{H}_{1}$ - The price of gold on the Iran's market have been affected by the markets of exchange rate.

Gold price on the domestic market was always regarded and as a significant variable is in the interest of investors, note that gold produce no income, so intrinsic value and its price is influenced by other variables in the economy [16]. There is no difference between gold global market and the gold in the domestic market that is likely to be directly affected by the global market. But, there are other factors affecting the economy as a unique economic conditions and the effects of the recent economic sanctions led to confusion in the analysis of the relationships between variables. The second hypothesis of the study is as follows.

$\boldsymbol{H}_{2^{-}}$The price of gold in the domestic market is affected by the global price of gold.

Another issue that has been widely discussed and debated, is the impact of fluctuations of the oil world prices on the domestic price of gold. The intellectual curiosity and policy pragmatism have focused on those commodities which include oil and precious metals particularly gold [25], so in the third hypothesis we are looking to confirm this issue, the following third hypothesis is expressed as bellow.

$\boldsymbol{H}_{3}$ - The price of gold on the market of Iran is affected by the price of global oil.

In recent years, speculations about influence of Security Council economic sanctions against Iran are made various ideas confirm or rejection of it. For example, in many researches government policies effect on real price of gold [19]. Therefore, this study sought to examine the documentation of effects of each Security Council statements against Iran for a detailed assessment, so the fourth hypothesis is stated as follows.

$\boldsymbol{H}_{4}$ - Economic sanctions against Iran had a significant impact on gold prices in the domestic market.

\subsection{Statistical Results}

Due to the nature of the subject, to evaluate the gold price, exchange rate and oil world price and other variables introduced in the literature on Iran's economy, in this study vector autoregression (VAR), has been used. This method is used when there is no recognizable criteria between endogenous and exogenous variables. Therefore in transfer function, all variables are considered endogenous [9]. The prediction of this method in many cases is better than the results of any complex methods such as simultaneous equations [11].

In this regard, according to Table 3, Akaike information criteria (AIC), Schwarz - Bayesian criterion (SBC), LR Statistic and modified LR statistic have been used to determine the optimal degree of VAR model. AIC and SBC grades are introduced 1 and 2 as the optimal degree. Based on modified LR statistics the optimized degree 1 is rejected and the optimized degree 2 is accepted as optimal level. In this interpretation, the degree VAR (2) model is selected as the optimum degree.

Table 3: statistic test to determine the optimal lag of VAR

\begin{tabular}{|l|c|c|c|}
\hline Lag & AIC & SBC & Adjusted LR test \\
\hline 0 & -61935.9 & -61935.9 & $62017.6[.000]$ \\
\hline 1 & -29359.7 & $-29621.6^{*}$ & $1360.0[.000]$ \\
\hline 2 & $-29161.2^{*}$ & -29685.1 & $805.9539[.434]$ \\
\hline 3 & -29209.6 & -29995.4 & $710.1830[.386]$ \\
\hline 4 & -29254.2 & -30301.9 & $607.2232[.410]$ \\
\hline 5 & -29289.0 & -30598.7 & $486.3337[.661]$ \\
\hline
\end{tabular}

*The optimum degree

\footnotetext{
${ }^{1}$ Security Council Statement 1803, which was passed on the third of March 2008, this statement was first imposed sanctions on Iran's economy as including import and export control particularly in the case of dual-use goods.

${ }^{2}$ Security Council Statement 1835, which was adopted on 27 September 2008 to continue and intensify in the previous sanctions.

${ }^{3}$ Security Council Statement 1929, which was adopted on 9 June 2010, which have been associated with previous statements, including sanctions on banking, insurance and inspection ship in order to decrease development trend of the Iran economy.

${ }^{4}$ Security Council Statement 1984, which was adopted on 9 June 2011, by re-emphasizing on previous sanctions against Iran and more cooperation of member states in the implementation of further sanctions against Iran.

${ }^{5}$ Security Council Statement 2049, enacted on 7 June, 2012, which is caused by the upheaval in recent months that attacked to Iran's oil export and Iran's central bank.
} 
Due to the optimal lag, the model for the study based on the VAR model in matrix form is expressed as follows:

$\mathrm{Y}_{\mathrm{n}}=\mathrm{C}_{\mathrm{n}}+\sum_{t=1}^{2}\left[a_{\mathrm{n}, \mathrm{t}} \mathrm{GC}(-\mathrm{t})+b_{\mathrm{n}, \mathrm{t}} \mathrm{OW}(-\mathrm{t})+c_{\mathrm{n}, \mathrm{t}} \mathrm{GO}(-\mathrm{t})+d_{\mathrm{n}, \mathrm{t}} \mathrm{DR}(-\mathrm{t})+e_{\mathrm{n}, \mathrm{t}} \mathrm{FR}(-\mathrm{t})+f_{\mathrm{n}, \mathrm{t}} \mathrm{II}(-\mathrm{t})+g_{\mathrm{n}, \mathrm{t}} \mathrm{UN} 1(-\mathrm{t})+h_{\mathrm{n}, \mathrm{t}} \mathrm{UN} 2(-\mathrm{t})+\dot{i}_{n, \mathrm{t}} \mathrm{UN} 3(-\right.$ $\mathrm{t})+j_{n, t} U N 4(-t)+k_{n, t} U N 5(-t)+\varepsilon_{1}$

Where $Y_{n}$ is equal to any of the following variables:

$\mathrm{Y}_{\mathrm{n}}=\{\mathrm{GC}, \mathrm{OW}, \mathrm{GO}, \mathrm{DR}, \mathrm{FR}, \mathrm{II}, \mathrm{UN} 1, \mathrm{UN2}$, UN3, UN4, UN5 $\}$

According to the proposed model, the six equation system components are intended to identify the effects of variables on each other.

In the time series data, before analysis and estimation of the model equations, the unit root test should be conducted to determine time series variables stability [11].

In the initial review this will be visible that all variables are not stable, because all of them are prices in period of time. Estimating the model using non-stationary variables can lead to spurious regression that leads to misleading. Therefore, to avoid spurious regression, we will turn to co-integration model. From the co-integration methods, we used the EngelGranger Two-steps Test. The Engel - Granger investigated whether residues from the regression model (as a linear combination of non-stationary variables that includes several series: gold price in domestic market, global oil price, free market exchange rate, the official rate and global gold price) is stable or not? The null hypothesis is shown that the residuals are not stable and alternative hypothesis is stated that the residuals are stable.

Based on the results in Table 4, the Schwarz-Bayesian Criterion (SBC), which has been the basis for determining the optimal interval, the optimal interval will be 2. Computational statistics at interval of two is equal to -8.7280 and since it is higher than the critical value -4.4283 (in absolute terms), the null hypothesis that is non stability is rejected. So the leftovers from the estimated equation are stable and co-integration between model variables are accepted.

Table 4: Unit Root Test for Lags

\begin{tabular}{|l|c|c|c|c|}
\hline Lag & Test Statistic & AIC & SBC & HQC $^{6}$ \\
\hline DF & -10.1820 & -18826.5 & -18829.1 & -18827.5 \\
\hline ADF(1) & -10.4915 & -18824.5 & -18829.7 & -18826.4 \\
\hline ADF(2) & -8.7280 & -18811.3 & $-18819.1^{*}$ & -18814.2 \\
\hline ADF(3) & -8.3075 & -18812.0 & -18822.4 & -18815.9 \\
\hline ADF(4) & -7.3714 & -18807.0 & -18820.1 & -18811.9 \\
\hline ADF(5) & -7.7009 & -18805.2 & -18821.0 & -18811.1 \\
\hline
\end{tabular}

In this study, to illustrate the changes in the coin price variables (GC) and the dollar exchange rate (DR) the filter Hodryk Prescott (to remove trend of time influenced variables) is used. Figure 1 is shown the actual volatility of gold price and dollar exchange rate for the years of studies (2007-2012) based on the Hodryk - Prescott filter.

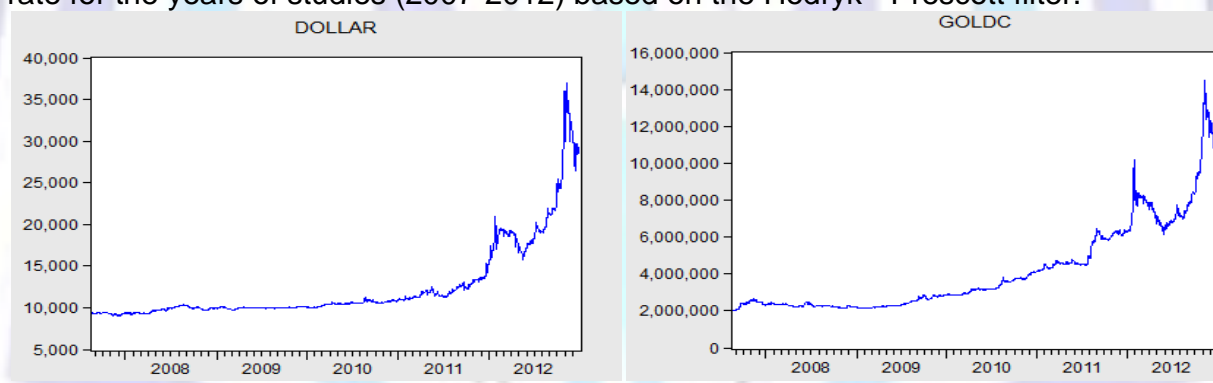

Figure 1: Gold price volatility (right) and the exchange rate volatility (left) filtered based on Hodryk - Prescott

As it is evident from the figure 1 the actual trend of these two variables are the same at a glance. These analyses are discussed in the following section.

\section{Results Analysis}

For estimating and examining the research model, at the first we will signify the dummy variables representing Security council statements against Iran, the initial evaluation indicates ineffectiveness two first statements, this means the Security council statement 1803 and 1835, Therefore, these two variables removed from the model to improve the model specify. We estimate results according to Vector Autoregression Models (VAR). To do it we need to separate endogenous Variables from exogenous Variables. Endogenous variables in this study is include GC, DR, FR and II, and the exogenous variables is include GO, OW and five security statements UN1, UN2, UN3, UN4 and UN5. To estimate our VAR model, we evaluate dummy variables for recognition of each price shock and the result is shown in Table 5.

Table 5: Results of Hypothesis Testing Dummy Variables Significant

\begin{tabular}{|l|c|c|c|c|c|}
\hline & Un1 & Un2 & Un3 & Un4 & Un5 \\
\hline LR Test of Restriction VAR & $1.8564[.762]$ & $6.6152[.158]$ & $2.5332[.639]$ & $15.4116[.004]$ & $37.8613[.000]$ \\
\hline
\end{tabular}

According to Table 5 and the LR statistic and the minimum significance level for each of the statements of the Security council (dummy variables) the null hypothesis based on non-meaningful of UN4 and UN5 is not rejected and the alternative hypothesis will be accepted. In other words, among the five statements imposed on Iran over the past five years, statement 1984 emphasized the cooperation of Member States to impose further sanctions and more importantly

${ }^{6}$ Hannan-Quinn Criterion 
emphasizes statement 2049 on Iran oil embargo and sanctions on dealings with Iran's central bank have very significant impact on the analysis and especially in the second half of 2012's price fluctuations.

Another point is used the Granger causality test for examined gold coin price affected by other endogenous variables and the result of this test implied that based on LR statistic (192.7744) and minimum significance level (0.000) null hypothesis (do not transmission of shocks from other endogenously variables on gold coin price) is rejected and the alternative hypothesis will be accepted. This means, gold coin price is affected by all of three endogenous variables (free market exchange rate, official rate and inflation index).

Estimation of VAR model in formed of four endogenous variables is described in Table 6:

Table 6: The Acquired Results of VAR Model

\begin{tabular}{|l|c|c|c|c|}
\hline & GC & DR & II & FR \\
\hline R-Squared & 0.99772 & 0.99519 & 0.99963 & 0.99626 \\
\hline Adj. R-Squared & 0.99769 & 0.99516 & 0.99963 & 0.99624 \\
\hline F-Statistic & $75570.5[0.000]$ & $36018.6[0.000]$ & $474842.1[0.000]$ & $46344.6[0.000]$ \\
\hline Akaike AIC & -18341.8 & -10166.2 & -2092.4 & -7659.7 \\
\hline Schwartz SC & -18365.4 & -10189.9 & -2116.0 & -7683.3 \\
\hline DW-Statistic & 1.9344 & 1.8163 & 2.0973 & 2.1519 \\
\hline
\end{tabular}

As can be seen, each of the models has a high coefficient determination $\left(\mathrm{R}^{2}\right)$ and acceptable statistics as follow: $\mathrm{GC}=-198059.4+0.8810^{*} \mathrm{GC}(-1)+56.8884^{*} \mathrm{DR}(-1)-99.0028^{*} \mathrm{II}(-1)-45.2459^{*} \mathrm{FR}(-1)+372.3287^{*} \mathrm{OW}+417.0983^{*} \mathrm{GO}+$ $47627.8 * U N 4-71195.3 * U N 5+\varepsilon$

$\mathrm{DR}=-15.1216+0.8584 \mathrm{E}-4^{\star} \mathrm{GC}(-1)+0.95262^{\star} \mathrm{DR}(-1)-0.92708^{\star} \mathrm{II}(-1)+0.5794^{\star} \mathrm{FR}(-1)-0.08982^{\star} \mathrm{OW}-0.11557^{\star} \mathrm{GO}+$ $8.7308 * U N 4+265.2949 * U N 5+\varepsilon$

$\mathrm{FR}=123.7880-0.5307 \mathrm{E}-5^{\star} \mathrm{GC}(-1)+0.0028^{\star} \mathrm{DR}(-1)+0.61629^{\star} \mathrm{II}(-1)+0.97369^{\star} \mathrm{FR}(-1)+0.04456^{\star} \mathrm{OW}-0.0025^{\star} \mathrm{GO}-$ $11.0632 * \mathrm{UN} 4-25.3663^{*} \mathrm{UN} 5+\varepsilon$

$\mathrm{II}=-0.84838+0.3492 \mathrm{E}-6^{\star} \mathrm{GC}(-1)-0.6446 \mathrm{E}-4^{*} \mathrm{DR}(-1)+0.98815^{\star} \mathrm{II}(-1)+0.3206 \mathrm{E}-3^{\star} \mathrm{FR}(-1)-0.1432 \mathrm{E}-3^{\star} \mathrm{OW}-0.1289 \mathrm{E}-$ $3^{*} \mathrm{GO}-0.15576 * \mathrm{UN} 4+0.2755^{*} \mathrm{UN} 5+\varepsilon$

And by removing the non-valid variables in significant level $99 \%$, the models are as follows:

$\mathrm{GC}=+0.8810^{*} \mathrm{GC}(-1)[0.000]+56.8884^{\star} \mathrm{DR}(-1)[0.000]-45.2459^{\star} \mathrm{FR}(-1)[0.001]$

$47627.8^{*} \mathrm{UN} 4[0.001]-71195.3^{*} \mathrm{UN} 5[0.001]+\varepsilon$

$\mathrm{DR}=0.8584 \mathrm{E}-4^{*} \mathrm{GC}(-1)[0.005]+0.95262^{*} \mathrm{DR}(-1)[0.000]+265.2949 * \mathrm{UN} 5[0.000]+\varepsilon$

$\mathrm{FR}=123.7880[0.007]+0.61629^{*} \mathrm{II}(-1)[0.001]+0.97369^{*} \mathrm{FR}(-1)[0.000]+\varepsilon$

$\mathrm{II}=0.3492 \mathrm{E}-6^{*} \mathrm{GC}(-1)[0.000]+0.98815^{*} \mathrm{II}(-1)[0.000]+0.3206 \mathrm{E}-3^{*} \mathrm{FR}(-1)[0.010]+\varepsilon$

Also according to the information criteria such as AIC and SBC, the first model (gold coin price based model) with the values $\mathrm{AIC}=-18365.4$ and $\mathrm{SBC}=-18341.8$ is recognized as the best model. In other words, the results suggest that despite the effect of fluctuations of the gold coin price on the inflation index in Iran, but is not affected by it. Dollar free market exchange rate and gold coin price fluctuations have an additive effect on each other, However, the exchange rate fluctuations have severe impact on the gold coin price and it represents the exchange rate changes with a lag will be change price of gold coin, so the first hypothesis that means the price of gold on the Iran's market have been affected by dollar exchange rate with coefficient 56.8884 [.000] will be accepted.

Dollar official rate of central bank of Iran is affected by inflation index and also is a positive affecting factor on the rate of free market Dollar, therefore leads to mistrust in market and increase demand of Dollar as an investment asset to preserve purchasing power of money. About fluctuations in the market and gold coin price affected by exogenous variables i.e., the second and third research hypothesis, it is noteworthy that gold coin price in domestic market by a coefficient of 417.098[0.000] is affected by gold world price and indicates that second research hypothesis will be accepted. In case of the third hypothesis, results have been shown no influence by world oil prices and this case is expectable because Iran is an exporter in petrochemical industry and independent of domestic economic variables from international price of oil and oil products is justified, therefore, the third hypothesis is not accepted. Finally, in relation to the impact of global sanctions against Iran, the results indicate that according to the five statements of the Security council during the period of the study, only two statement i.e. statement 1984, with emphasis on the global association about economic sanctions against Iran and statement 2049, with emphasis on the oil industry sanction and intercourse bounded with Iran's central bank, have significantly influenced on fluctuations of gold coin price (increase in gold coins prices) therefore, the fourth research hypothesis is accepted by $99 \%$ significance level.

6- Summary and conclusions

This study examined the relationship between endogenous and exogenous variables affecting the price of gold in domestic market. The main goal of this research is to provide the official statistics on existing relationships between the variables and documenting these relationships to predict the future and selection of more efficient investment option. The main focus of research is on the relationship between gold price and free market rate of Dollar in relation to other economic variable. Causality functions shows that gold coin price in Iran consistent on expectations is affected by the world price of gold while not affected by the impact of international oil prices.

Gold coin price not only is influenced on Dollar free market rate but also is very severe affected by it, therefore it is possible to forecast the gold coin price with use of tracing the Dollar rate fluctuations and also that the free market rate of Dollar price's fluctuations is more stable than gold coin price fluctuations. The sanctions imposed by the Security council of united nation in the research period against Iran should also mentioned that only the statement 2049, adopted in June 2012, has significant effect on fluctuations of gold coin price and free market rate of US Dollar in Iran domestic market. 


\section{REFERENCES}

[1] Aggarwal, R., \& Soenen, L. A. 1988, "The nature and efficiency of the gold market", Journal of Portfolio Management, 14, 18-21.

[2] Baffes, J., 2007, "Oil spills on other commodities", Resources Policy, 32, 126-134.

[3] Beckers, S., Soenen, L., 1984. " Gold: more attractive to non-US than to US investors?", Journal of Business Finance and Accounting, 11, 107-112.

[4] Blose, L,. 2010, "Gold Prices, Cost of Carry and Expected Inflation", Journal of Economics and Business, 62, 3547.

[5] Ciner, C., 2001. "On the long-run relationship between gold and silver: a note", Global Financial Journal, 12, 299303.

[6] Davidson, S., Faff, R. \& Hillier, D., 2003. "Gold factor exposures in international asset pricing", Int. Financial Markets Inst. Money, 00, 1-19.

[7] Draper, P., Faff, R., Hillier, D., 2006. "Do precious metals shine? An investment perspective", Financial Analysts J. 62, 98-106.

[8] Egan, P., Peters, C., 2001. "The performance of defensive investments", J. Altern. Investments, 4, 49-56.

[9] Enders, W., 2009, "Applied Econometrics Time Series", Wiley, 3th edition.

[10] Goodman, B., 1956. "The price of gold and international liquidity", J. Finance, 11, 15-28.

[11] Gujarati, D., 2003. "Basic Econometrics", McGraw Hill, Boston.

[12] Hammoudeh, S., Yuan, Y., 2008. "Metal volatility in presence of oil and interest rate shocks", Energy Economics, $30,606-620$.

[13] Johnson, R., Soenen, L., 1997. "Gold as an investment asset perspectives from different coutries", J. Investing, 6, 94-99.

[14] Kaufmann, T.D., Winters, R.A., 1989. "The price of gold: a simple model”, Resources Policy, 15 (4), $309-313$.

[15] Le Pen, Y. \& Sevi, B. 2012, "Futures trading and the excess comovement of commodity prices", Electronic copy available at: http://ssrn.com/abstract=2191659.

[16] Millar, w. R. P. 2007, "The Relevance and importance of Gold in the World Monetary System", Valu-Trac Research, Electronic copy available at: http://valu-trac.com.

[17] Pindyck, R., Rotemberg, J., 1990. "The excess co-movement of commodity prices", Economic Journal, 100, 1173-1189.

[18] Pukthuanthong, K. \& Roll, R., 2011. "Gold and the Dollar (and Euro, Pound and Yen)", Journal of Banking \& Finance, 35, 2070-2083.

[19] Salant, S. W. \& Henderson, D. W., 1978. "Market Anticipations of Government Policies and the Price of Gold", The Journal of Political Economy, 86, (4), 627-648.

[20] Sari, R., Hammoudeh, S., Ewing, B.T., 2007. "Dynamic relationships between oil and metal commodity futures prices", Geopolitics of Energy, 29 (7), 2-13.

[21] Security Council, 2012. Department of Public Information, News and Media Division, New York.

[22] Shafiee, S. \& Topal, E., 2010, "An Overview of global gold market and gold price forecasting", Resources Policy, 35, 178-189.

[23] Sherman, E. J., 1982. "Gold: A conservative, prudent diversifier", Journal of Portfolio Management, 8, $21-27$.

[24] Solt, M., Swanson, P., 1981. "On the efficiency of the markets for gold and silver", J. Business, 54, 453-478.

[25] Soytas, U., Sari, R., Hammoudeh, S. \& Hacihasanglu, E., 2009, " World oil prices, precious metal prices and macroeconomy in Turkey", Enegry Policy, 37, 5557-5566.

[26] Tully, E., \& Lucey, B. M. 2007. "A power GARCH examination of the gold market", Research in International Business and Finance, 21, 316-325. 